\title{
RESPONSABILIDADE SOCIAL DO BIBLIOTECÁRIO ENQUANTO MEDIADOR LITERÁRIO: ANÁLISE NOS CURRÍCULOS DOS CURSOS DE GRADUAÇÃO EM BIBLIOTECONOMIA NO NORDESTE DO BRASIL
}

\author{
SOCIAL RESPONSIBILITY OF THE LIBRARIAN AS A \\ LITERARY MEDIATOR: ANALYSIS IN THE CURRICULA \\ OF UNDERGRADUATE COURSES IN LIBRARIANSHIP IN \\ THE NORTHEAST OF BRAZIL
}

Laiana Ferreira de Sousa ${ }^{1}$

Rayan Aramís de Brito Feitoza ${ }^{2}$

\begin{abstract}
RESUMO
Introdução: Discute a importância da formação de competências leitoras do bibliotecário no âmbito pessoal e profissional, para constituição deste profissional enquanto mediador da leitura e formador do sujeito-leitor no âmbito das bibliotecas. Objetivo: Identificar as disciplinas que abordam a temática leitura sob a ótica da responsabilidade social do bibliotecário enquanto mediador literário, por meio dos currículos dos cursos de Biblioteconomia da região Nordeste do Brasil. Metodologia: Trata-se de uma pesquisa documental, de caráter exploratório e descritivo, e de abordagem qualiquantitativa. A coleta dos dados foi realizada via web, através da recuperação dos Projetos Pedagógicos de Curso (PPC) e das matrizes curriculares dos cursos. Posteriormente, realizou-se um mapeamento dos componentes curriculares que versam sobre a temática da leitura nas disciplinas dos cursos de biblioteconomia no Nordeste. A análise envolveu as disciplinas obrigatórias oferecidas pelo universo das nove Universidades Federais da Região que ministram o curso de Biblioteconomia. Resultados: Após o mapeamento e identificação das disciplinas obrigatórias com temáticas sobre leitura no âmbito da responsabilidade social do

\footnotetext{
${ }^{1}$ Doutoranda em Ciência da Informação pelo Programa de Pós-Graduação em Ciência da Informação da Universidade Federal da Paraíba (PPGCI/UFPB). E-mail: laiana_ffsousa@hotmail.com

2 Mestrando em Ciência da Informação pelo Programa de Pós-Graduação em Ciência da Informação da Universidade Federal da Paraíba (PPGCI/UFPB). E-mail: rayanbritof@gmail.com
} 
bibliotecário mediador, tivemos um número de seis Instituições Federais, destacandose os cursos de Biblioteconomia. Conclusão: A pesquisa evidenciou que a formação do bibliotecário ainda é pouco voltada para capacitar profissionais para interagir com as ações de mediação de leitura, formação e promoção de leitura no âmbito social. A grande maioria das IES ofertam no máximo duas disciplinas obrigatórias, as quais apresentam questões voltadas para a práxis da leitura na formação do bibliotecário.

Descritores: Bibliotecário. Mediação da Leitura. Responsabilidade Social.

\section{INTRODUÇÃO}

A informação tem o poder de nos trazer o conhecimento que concebemos, principalmente através da leitura, a qual possibilita as trocas simbólicas e a veiculação de ideias, independentemente da forma do seu suporte ou do seu conteúdo. Esta, por sua vez, não se efetiva em ação isolada ou linear, pelo contrário, ali se misturam experiências vividas, memórias afetivas, sentimentos e motivações que tornam esta prática diferente para cada leitor. De modo amplo, a leitura é a capacidade do ser humano de compreender o mundo à sua volta, interpretando sons, letras, imagens e símbolos em um processo contínuo de construção de significados. Já que, conforme aborda Chartier (1998, p. 77), "a leitura é sempre apropriação, invenção, produção de significados."

Portanto, a leitura é um instrumento de transformação social e de construção de cidadania, pois tornar-se um sujeito crítico e atuante na sociedade contemporânea está diretamente condicionado à oportunidade de leitura. Visto que convivemos numa sociedade letrada dotada de uma carga cultural que é transmitida e permeada a partir da leitura, seja ela escrita ou imagética. Estar fora desse circuito de leitores é estar excluído, não só do mundo da leitura, mas também, sobretudo, do acesso à informação.

Apesar disso, seja por questões culturais ou socioeconômicas, a leitura ainda não faz parte do cotidiano da população brasileira, o que afeta diretamente no desenvolvimento e crescimento do país. Sem leitura o ser humano não desenvolve sua percepção crítica, não compreende o seu papel no âmbito social, tampouco apropria-se dele como espaço de direito. Essas questões só evidenciam que a prática da leitura é fator preponderante para 
constituição de sujeitos conscientes dos desdobramentos sociais, políticos, econômicos, linguísticos e psicológicos.

No Brasil, embora o número de pessoas alfabetizadas ou em fase de alfabetização está crescendo, pesquisas realizadas recentemente mostram que o número de leitores ainda não tem acompanhado esse ritmo. Os dados levantados pela pesquisa Retratos de Leitura no Brasil' assinalam que apesar do crescimento do número de leitores apontados na última pesquisa realizada em 2015, uma parcela significativa da população tem dado pouca ou nenhuma importância à leitura, ao menos na sua forma tradicional.

$O$ que nos faz indagar sobre o abismo que existe entre saber ler e o não interesse pela leitura. A resposta pode estar na mediação de leitura e como a experiência dessa prática vem sendo exercida nos espaços socialmente constituídos, a exemplo do campo de atuação dos profissionais formados em biblioteconomia.

O bibliotecário é identificado neste texto como um profissional que possui diferentes papéis na sociedade e, portanto, deve apresentar múltiplas competências que variam de acordo com o seu espaço de atuação. Em especial nas bibliotecas públicas e escolares, ele deve apresentar perfil de educador, leitor e principalmente mediador social, quando se utiliza de artifícios para aproximar o leitor do texto literário. Esta prática é muito decisiva para a aprendizagem do ser humano, constituindo-se como um processo básico no qual o indivíduo é capaz de receber informações e interagir socialmente.

Para que essa prática seja levada adiante, é preciso que esse profissional reconheça sua responsabilidade de mediador social e atue de modo a contribuir para a formação de leitores. Principalmente, se lembrarmos que um grande número de brasileiros só tem acesso a livros e outras fontes/recursos de leitura na biblioteca. Nesse ponto, destacamos a função

\footnotetext{
${ }^{1}$ A pesquisa Retratos de Leitura no Brasil é a única pesquisa, em âmbito nacional, que tem por objetivo avaliar o comportamento leitor do brasileiro. Os últimos resultados da pesquisa apontaram para um crescimento à nível nacional de leitores (para pesquisa leitor é aquele que leu pelo menos parte de um livro nos últimos três meses), os índices de leitura passaram de 4 livros por ano, em 2011, para 4,97 em 2015. Entretanto, no Nordeste, os números não evidenciaram crescimento, permanecendo a mesma média de 2011. Disponível em:<http://www.publishnews.com.br/estaticos/uploads/2016/05/zPurbYyLtHcyykd8onwpYk7qz 6lopAWUYdDIHbLRAKy1FQWdCNf64T4VIOIZAP7BUJAxYsxkbY73VaWp.pdf>. Acesso em: 19 de ago. de 2017.
} 
social deste profissional na sociedade, quando busca meios de prover acesso à informação, tentando eliminar as barreiras da exclusão social que restringe o acesso ao livro, ao conhecimento.

Entretanto, é importante salientar, que esse processo de apropriação do papel social de mediador e formador de leitura por parte dos bibliotecários, deve ser estruturado desde as suas primeiras interações com o curso de Biblioteconomia, já que dentre os papéis deste profissional está a disseminação e promoção do acesso à informação. Além disso, é de suma importância que durante a formação em Biblioteconomia esse profissional não só adquira competências para conquistar o seu usuário, mas que seja sensibilizado para a necessidade de leitura, principalmente no que diz respeito às suas práticas enquanto leitor.

É durante a graduação em Biblioteconomia, através de disciplinas e projetos de pesquisa e de extensão, que se espera que o entendimento do papel social do bibliotecário deva ser construído e elucidado. A possibilidade de envolvimento com a sociedade em geral e os variados caminhos para a mediação da leitura fazem corroborar com a visão de Almeida Junior e Ana Bicheri quando os autores argumentam que "[...] não bastam conhecimentos técnicos da área de biblioteconomia, educação e leitura. Ele [bibliotecário] precisa se envolver com sua comunidade, saber e gostar de trabalhar com crianças, adolescentes e adultos." (ALMEIDA JUNIOR; BICHERI, 2013, p. 44).

A presente pesquisa buscou responder a seguinte questão: as estruturas curriculares dos cursos de Biblioteconomia das IFES nordestinas incluem disciplinas obrigatórias cujos conteúdos estejam orientados para Responsabilidade Social na perspectiva da mediação de leitura? Diante disso, este artigo apresenta a importância da formação leitora do bibliotecário no âmbito pessoal e profissional, para constituição deste profissional enquanto mediador da leitura e formador do sujeito-leitor no âmbito das bibliotecas. Parte-se do pressuposto de que, somente através do entendimento e sensibilização para a importância da leitura na vida das pessoas, que este profissional poderá ser atuante no que diz respeito à formação de leitores.

Para adentrar no estudo proposto, esta pesquisa tem como objetivo identificar as disciplinas que abordam a temática leitura sob a ótica da 
responsabilidade social do bibliotecário enquanto mediador literário, por meio dos currículos dos cursos de Biblioteconomia da região Nordeste do Brasil. Para poder, assim, viabilizar a importância de desenvolver nos futuros profissionais, competências voltadas para a responsabilidade social de mediar a leitura nos espaços de atuação.

\section{PAPEL SOCIAL DE MEDIADOR DA LEITURA DO BIBLIOTECÁRIO}

A fim de dar conta da missão de compartilhar dos bens naturais, sociais e culturais, a Universidade desenvolve atividades específicas, quais sejam, o ensino, a pesquisa e a extensão. Neste contexto acadêmico, dada a natureza específica de seu processo, a educação superior tem na pesquisa o ponto básico de apoio e sustentação. Entretanto, necessita das demais dimensões para manter seu objetivo de produzir e fazer circular o conhecimento. Nessa tríade, pode-se notar a existência de um viés epistemológico e pedagógico, mas também social.

A extensão é relevante para a produção do conhecimento, já que tem como referência objetiva os problemas reais e concretos que se relacionam com a vida da sociedade envolvente. É o que alimenta e faz com que a pesquisa não se torne desinteressada ou neutra, por exemplo. Ao sair dos muros universitários os estudantes e professores contribuem para 0 desenvolvimento social, mas principalmente aperfeiçoam suas competências técnicas e retornam para os espaços acadêmicos com novos olhares e perspectivas para a sala de aula.

O curso de Biblioteconomia busca formar um profissional que valorize os aspectos sociais e humanitários da sociedade, que se envolva com o interesse da comunidade sempre pautado no seu papel de produzir, organizar e disseminar informação, assim como oferecer condições para construção do conhecimento. É importante que ele compreenda seu papel como facilitador do acesso à informação, mas principalmente como mediador desse processo, fazendo parte da formação de outros indivíduos através das práticas de leitura.

Frente ao atual cenário de crescentes complexidades em torno da ampla produção e difusão de informação, cumpre a este profissional buscar formas de 
fomentar a leitura nos espaços de produção do conhecimento, permitindo a apropriação da informação e contribuindo para o desenvolvimento intelectual de seus usuários, por isso a importância da tríade ensino, pesquisa e extensão.

Contudo, para que o estudante compreenda seu papel social no âmbito da sociedade é imprescindível que conviva de perto com o impacto de suas ações na vida das pessoas. Sem isto, tampouco saberá compreender a importância do seu trabalho enquanto agente socializador.

Essas discussões ganharam mais notoriedade quando a Responsabilidade Social passou a ser uma das dimensões de avaliação do Sistema Nacional de Avaliação da Educação Superior (SINAES), o que, de certam forma, contribuiu com o entendimento desta ação social e suas diferenças com as empresas filantrópicas. Apesar de não citar a temática "Responsabilidade Social", sabe-se de sua inserção no sistema de avaliação, uma vez que este sistema busca identificar ações voltadas para o contexto social externo à universidade, mas vinculada a esta. Esta responsabilidade social é vista como "[...] toda e qualquer ação que possa contribuir para a melhoria da qualidade de vida da sociedade [...] feita de maneira continuada e não fortuita" (ASHLEY, 2003, p. 7).

Além disso, a função de mediador do bibliotecário favorece, entre outros aspectos, a seleção, organização, disponibilização do acervo/informações e intervenção nas práticas de leitura no ambiente em que atua, também contribuindo na formação de leitores.

Tratando-se de leitura, o mediador é aquele que medeia, intervém, aproxima o leitor do texto. Em outras palavras, o promotor da relação leitor objeto - leitura. Mas também aquele que pode despertar no sujeito o interesse e a curiosidade pelo mundo das leituras, especialmente a literária. Para isso, ele se utilizará de artifícios que possam chamar a atenção do futuro leitor, seja através da contação de histórias, da roda de leitura de textos literários, oficina ou de outra atividade integradora.

Almeida Junior (2006, p. 53-54), discorre sobre a postura do bibliotecário mediador de leitura ao mencionar que o bibliotecário adequado é aquele que 
[...] está em constante questionamento; [...] que procura conhecer sua área de atuação; [...] que tem consciência de que o usuário é seu fim último; que sabe que informações com as quais lida não são neutras e imparciais; que está sempre procurando conhecer os motivos que há por trás de suas ações; [...] que sabe que a informação é imprescindível para a formação do cidadão. [...] é aquele que reconhece sua profissão como importante e necessária para a sociedade e se reconhece como um agente de transformação social. [...]

Diferentemente dos professores, o bibliotecário não tem como incumbência primeira cumprir conteúdos curriculares, grade curricular, etc. Sua participação na formação do leitor, e no incentivo à leitura deve se desprender da cobrança de leitura para aquisição de conteúdo ou normas gramaticais. "Pensamos que ler um texto é compreendê-lo, isto é, descobrir-lhe a chave. Quando de fato nem todos os textos são feitos para serem lidos nesse sentido." (CHARTIER, 1996, p. 234). O papel do bibliotecário enquanto mediador social não é o de exigir ou induzir a leitura por obrigação, mas de sensibilizar a leitura por amor, por desejo ou simples curiosidade.

Os antigos currículos dos cursos de Biblioteconomia eram muito técnicos e não ofereciam a capacitação necessária a este profissional para trabalhar em bibliotecas de cunho social e educativo. "As críticas eram dirigidas, principalmente, ao conteúdo dos programas e métodos de ensino, cujos objetivos pareciam ser muito voltados à aquisição de prática no uso de normas e tabelas." (MULLER, 1985, p. 10).

No momento de estágios, por exemplo, nem todos os alunos têm oportunidade de vivenciar a realidade de uma biblioteca púbica, comunitária ou escolar. Isso é refletido na postura do bibliotecário quando estes se deparam com esses espaços de atuação social, muitas vezes não reconhecendo o seu lugar e função. (ALMEIDA JUNIOR; BICHERI, 2013). Nesse aspecto, novamente, se repete a importância da formação do estudante de biblioteconomia, para que este apresente no seu perfil a competência, qualidade, característica e envolvimento necessário para atuar como mediador social.

O mais importante talvez seja o entendimento da profissão, ou seja, a definição do profissional que se deseja formar para o Brasil de hoje e do futuro a curto e médio prazo. A julgar pelos programas de disciplinas oferecidas até 1980, a motivação 
maior parece ter sido a organização de documentos e, em menor grau, da informação. A literatura profissional por outro lado, vem conclamando a classe para se reconhecer como agente social preocupado com o acesso do povo à informação, à educação e à cultura, com responsabilidades no desenvolvimento da ciência e da técnica, e em todos os aspectos da vida nacional e individual que dependam ou possam lucrar com acesso a informação (MULLER, 1985, p. 13).

É importante, que o curso de biblioteconomia propicie, através do conteúdo de suas disciplinas, condições para que o bibliotecário possa cumprir seu papel social e corresponder aos interesses da comunidade na solução de problemas sociais, através de currículos abertos e flexíveis que atendam às diversas necessidades dos contextos sócio educacionais, conforme cita Madruga (2008, p. 110): "A Biblioteconomia deve ter a preocupação em formar um profissional atual, capacitado, holístico que atenda a todos os sujeitos."

De acordo com as Diretrizes Curriculares Nacionais (DCN) para o curso de Biblioteconomia, o perfil dos formandos propõe:

[...] os egressos dos referidos cursos deverão ser capazes de atuar junto a instituições e serviços que demandem intervenções de natureza e alcance variados: bibliotecas, centros de documentação ou informação, centros culturais, serviços ou redes de informação, órgãos de gestão do patrimônio cultural etc (BRASIL, 2001, p. 32).

Nesse sentido, os currículos dos Cursos de Biblioteconomia precisam por meio de práticas pedagógicas inovadoras e emancipatórias, incentivar o aluno a pensar, refletir, bem como compreender seu papel enquanto agente social da leitura.

Por isso é de suma importância que durante a formação em Biblioteconomia esse profissional adquira competências para conquistar o seu usuário, devendo agir com criatividade, empenho e responsabilidade social. É preciso que esse profissional reconheça sua responsabilidade de mediador social e atue de forma a contribuir para a formação de leitores.

\section{METODOLOGIA}

Para que seja realizado um levantamento e mapeamento das estruturas curriculares dos cursos de Biblioteconomia no Nordeste brasileiro, dentro da 
espera Federal, com o objetivo de identificar disciplinas que buscam desenvolver competências voltadas para a responsabilidade social do bibliotecário enquanto mediador da leitura, serão utilizadas como metodologia a pesquisa exploratória, que segundo Gil (2010, p. 43) é a principal finalidade de desenvolver, esclarecer e modificar conceitos e ideias, tendo em vista, a formulação de problemas mais preciosos ou hipóteses pesquisáveis para estudos posteriores.

A pesquisa também é do tipo descritiva, já que "tem como objetivo primordial a descrição das características de determinada população ou fenômeno ou estabelecimento de relações entre variáveis" (GIL, 2010, p. 45). Além disso, nos utilizamos da pesquisa documental para análise das matrizes curriculares, que por si só representaram fontes objetivas de dados.

Sendo um estudo eminentemente documental, as principais fontes que compuseram o corpus da pesquisa foram os Projetos Pedagógicos de Curso (PPC) e as matrizes curriculares em vigor dos cursos de Biblioteconomia do Nordeste, na esfera Federal. Tais documentos foram colhidos diretamente do Sistema Integrado de Gestão de Atividades Acadêmicas (SIGAA) e dos sites dos Departamentos dos cursos estudados. As disciplinas ligadas à temática foram identificadas pela palavra "leitura", no título ou na ementa dos currículos analisados, porém foram excluídas as disciplinas atinentes à perspectiva do ensino de línguas, ou de sistemas de leitura (Braile) e da produção de livros. (Editoração).

Em síntese, foram selecionadas exclusivamente as disciplinas de natureza obrigatória aquelas que no próprio título ou na ementa remetiam para aspectos sociais da formação em Biblioteconomia.

O processo da análise se deu na busca de equivalência entre os conteúdos presentes nas ementas dos cursos que pudessem convergir para os aspectos de mediador social da leitura na formação profissional. 


\section{RESULTADOS}

Inicialmente, a partir de uma pesquisa realizada no site do e-MEC, contávamos com um universo de nove cursos de Biblioteconomia na região Nordeste da esfera Federal, são eles:

1) UFS - UNIVERSIDADE FEDERAL DE SERGIPE

2) UFAL - UNIVERSIDADE FEDERAL DE ALAGOAS

3) UFBA - UNIVERSIDADE FEDERAL DA BAHIA

4) UFC - UNIVERSIDADE FEDERAL DO CEARÁ - (FORTALEZA)

5) UFCA - UNIVERSIDADE FEDERAL DE CARIRI- (Juazeiro do norte CE)

6) UFMA - UNIVERSIDADE FEDERAL DO MARANHÃO

7) UFRN - UNIVERSIDADE FEDERAL DO RIO GRANDE DO NORTE

8) UFPB - UNIVERSIDADE FEDERAL DA PARAÍBA

9) UFPE - UNIVERSIDADE FEDERAL DE PERNAMBUCO

Após o mapeamento e identificação das disciplinas obrigatórias com temáticas sobre leitura no âmbito da responsabilidade social do bibliotecário mediador, tivemos um número de seis Instituições Federais, pois a UFAL não apresenta em seu currículo uma disciplina que aborde a leitura como temática central e a UFPE apresentava apenas uma optativa desta natureza, portanto, não se enquadrava na perspectiva da pesquisa. Não foi possível avaliar a matriz curricular da UFBA, pois a mesma encontra-se em construção e, apenas parcialmente, disponível no sítio eletrônico da instituição. Os PPC representaram as principais fontes de referência para análise desta pesquisa, os quais tivemos acesso online.

Muitas disciplinas que compõem o ciclo obrigatório em outros constituem disciplinas optativas ou eletivas. Para nossa pesquisa, interessava-nos o estudo de disciplinas comuns a todos os estudantes do curso de Biblioteconomia, uma vez, que não podemos garantir que todos os alunos tenham optado por fazer as disciplinas que remetem a leitura. 
Quadro 1 - Disciplinas de Leitura na UFC - Fortaleza

\begin{tabular}{|l|l|l|}
\hline DCN & SEMESTRE & DISCIPLINA \\
\hline $\begin{array}{l}\text { Área 1: } \\
\text { fundamentos Teóricos } \\
\text { da Biblioteconomia e } \\
\text { da Ciência da } \\
\text { Informação }\end{array}$ & Segundo & Teoria e Pratica da Leitura \\
\hline
\end{tabular}

Fonte: dados da pesquisa (2017)

Quadro 2 - Disciplinas de Leitura na UFCA - Cariri

\begin{tabular}{|l|l|l|}
\hline DCN & SEMESTRE & DISCIPLINA \\
\hline Área 1: & Segundo & Teoria e pratica da leitura \\
$\begin{array}{l}\text { Fundamentos Teóricos } \\
\text { da Biblioteconomia e } \\
\text { da Ciência da }\end{array}$ & & \\
Informação & & \\
\hline
\end{tabular}

Fonte: dados da pesquisa (2017)

Iniciamos nossa busca pelos cursos de Biblioteconomia ministrados pela UFC e UFCA. Ambos apresentam a mesma disciplina ofertada no segundo semestre do curso, Disciplina Teoria e Prática da Leitura, com carga horária de $64 \mathrm{~h}$, assim como a mesma descrição conceitual. A disciplina tem o enfoque nos processos da leitura e da escrita sob diferentes concepções. Além disso, busca enfatizar questões relativas ao sociointeracionismo, a estética da recepção e o letramento. Estuda as políticas de leitura no Brasil para contribuir na compreensão das atuais problemáticas da leitura/escrita, do livro, da biblioteca, da formação do leitor e das práticas leitoras.

Do conteúdo da ementa observou-se o caráter de educação complementar da disciplina e a formação de profissionais capacitados para desempenhar o papel de mediadores da leitura como também o de formador de leitores na sociedade. Apesar do currículo apresentar apenas uma disciplina obrigatória, nota-se a ênfase no ensino da teoria e da aplicação das práticas de leitura junto aos usuários de biblioteca.

Quadro 3 - Disciplinas de Leitura na UFPB

\begin{tabular}{|l|l|l|}
\hline DCN & SEMESTRE & DISCIPLINA \\
\hline $\begin{array}{l}\text { Área 1: Fundamentos Teóricos } \\
\text { da Biblioteconomia e da Ciência } \\
\text { da Informação }\end{array}$ & Primeiro & $\begin{array}{l}\text { História da Leitura e dos } \\
\text { Registros do Conhecimento }\end{array}$ \\
\hline $\begin{array}{l}\text { Área 1: Fundamentos Teóricos } \\
\text { da Biblioteconomia e da Ciência } \\
\text { da Informação }\end{array}$ & Quinto & Leitura e Produção de Textos \\
\hline
\end{tabular}

Fonte: dados da pesquisa (2017) 
O currículo do curso de Biblioteconomia da UFPB apresenta duas disciplinas obrigatórias, ambas com 64h. A disciplina História da leitura e dos registros do conhecimento é ministrada no primeiro semestre do curso e em seu conteúdo programático destaca as abordagens histórico-culturais e sociais da leitura e registros do conhecimento. Enquanto a disciplina Leitura e Produção de Textos tem seu enfoque na produção de textos técnico-científicos da área.

O grande diferencial desta instituição é o fato de dispor de duas disciplinas sobre a temática leitura, uma no início do curso e outra quase ao final do curso. O que demonstra que existe uma preocupação para enfatizar a importância da atuação do bibliotecário como formador de leitura quando o aluno está em vias de conclusão de curso.

Quadro 4 - Disciplinas de Leitura na UFRN

\begin{tabular}{|l|l|l|}
\hline DCN & SEMESTRE & DISCIPLINA \\
\hline $\begin{array}{l}\text { Área 1: Fundamentos Teóricos } \\
\text { da Biblioteconomia e da }\end{array}$ & Primeiro & $\begin{array}{l}\text { Prática de Leitura e Produção } \\
\text { de Textos }\end{array}$ \\
\hline $\begin{array}{l}\text { Área 1: Fundamentos Teóricos } \\
\text { da Biblioteconomia e da } \\
\text { Ciência da Informação }\end{array}$ & Segundo & $\begin{array}{l}\text { História do Livro e das } \\
\text { Bibliotecas }\end{array}$ \\
\hline
\end{tabular}

Fonte: dados da pesquisa (2017)

Num total de 38 disciplinas obrigatórias entre aulas teóricas e prática, selecionamos duas disciplinas que se adequam ao objetivo desta análise. Assim como as disciplinas curriculares do curso de biblioteconomia da UFCA e UFPB, a disciplina Prática de Leitura e Produção de Textos aborda a Leitura e a produção de textos com ênfase na textualidade e tipologia. O objetivo é aperfeiçoar as habilidades de leitura e escrita, mediante um trabalho integrado de análise e produção de textos.

Já a disciplina História do Livro e das Bibliotecas aborda a evolução dos diversos tipos de registros de conhecimento humano, assim como a origem e evolução da escrita. Seu grande diferencial está na abordagem da função social das bibliotecas através dos tempos e da figura do bibliotecário enquanto mediador social de leitura nos espaços das bibliotecas, como nos fala Gasque (2012, p. 157) 
O papel das bibliotecas pode ser enriquecido com a mediação dos bibliotecários nos processos de aprendizagem dos usuários, isto é, mais do que organizar a informação, os bibliotecários devem se preocupar em ajudar os usuários a buscá-la e usá-la.

O bibliotecário possui as competências necessárias para aproximar o leitor do texto, e principalmente, por meio da paixão pela literatura, consistindo em uma peça fundamental para a formação leitora.

Quadro 5 - Disciplinas de Leitura na UFMA

\begin{tabular}{|l|l|l|}
\hline DCN & SEMESTRE & DISCIPLINA \\
\hline $\begin{array}{l}\text { Área 1: } \\
\text { Fundamentos Teóricos } \\
\text { da Biblioteconomia e } \\
\text { da Ciência da }\end{array}$ & TERCEIRO & $\begin{array}{l}\text { História do Livro e das } \\
\text { Bibliotecas }\end{array}$ \\
$\begin{array}{l}\text { Informação } \\
\text { Área 1: }\end{array}$ & \\
$\begin{array}{l}\text { Fundamentos Teóricos } \\
\text { da Biblioteconomia e } \\
\text { da Ciência da } \\
\text { Informação }\end{array}$ & SEXTO & Leitura e Formação de \\
\hline
\end{tabular}

Fonte: dados da pesquisa (2017)

Dentre as 44 disciplinas obrigatórias constantes do programa, duas foram destacadas, uma vez que seus conteúdos sociais apresentavam aspectos voltados para leitura e formação de leitores. Após a análise das ementas da UFMA, identificou-se que o curso possui duas disciplinas obrigatória sobre a temática Leitura, com destaque no planejamento de atividades de leitura para crianças e jovens na escola e na biblioteca.

A ementa da disciplina Leitura e Formação de Leitores prevê um estudo bastante voltado para as práticas de mediação da leitura, abordando não somente a concepção de leitura como o processo de formação de leitores e as práticas de leitura na família, na escola e na biblioteca.

O que entra em consonância com o que Michéle Petit (2008), estudiosa da leitura e da formação do leitor, apresenta em seu livro Os jovens e a leitura: uma nova perspectiva, quando afirma que a biblioteca e a pessoa do bibliotecário também são mediadores importantes para a formação leitora. Contudo, segundo Petit (2008, p. 166), não é apenas a existência da biblioteca ou da escola "que desperta o gosto por ler, por aprender, imaginar, descobrir. É 
um professor, um bibliotecário que, levado por sua paixão, transmite-a através de uma relação individual".

Outra pesquisadora estudiosa da leitura, Vera Teixeira de Aguiar (2006), no artigo $O$ caminho dos livros: da biblioteca à comunidade, discute sobre as lacunas existentes na função do bibliotecário no que tange à formação de sujeitos leitores. Alega que não basta apenas dispor de um bom acervo físico para formação do leitor, e sim "o trabalho do bibliotecário como animador cultural" (AGUIAR, 2006, p. 259).

Quadro 6 - Disciplinas de Leitura na UFS - Sergipe

\begin{tabular}{|l|l|l|}
\hline DCN & SEMESTRE & DISCIPLINA \\
\hline $\begin{array}{l}\text { Área 1: } \\
\text { Fundamentos Teóricos } \\
\text { da Biblioteconomia e } \\
\text { da Ciência da }\end{array}$ & TERCEIRO & $\begin{array}{l}\text { Letramento e competência } \\
\text { informacional }\end{array}$ \\
\hline $\begin{array}{l}\text { Informação } \\
\text { Área 3: }\end{array}$ & \\
$\begin{array}{l}\text { Recursos e Serviços de } \\
\text { Informação }\end{array}$ & SEXTO & Mediação da Informação \\
\hline
\end{tabular}

Fonte: dados da pesquisa (2017)

Diferenciando-se das demais grades curriculares, a UFS apresenta, dentre suas 26 disciplinas obrigatórias, a disciplina Letramento e Competência informacional, a qual tem como objetivo formar o estudante para dominar os conhecimentos sobre a prática leitora e seu relacionamento com os ambientes informacionais e unidades de informação de exercício profissional do Bibliotecário e Documentalista, já que o curso recebe uma nomenclatura diferente: Curso de Biblioteconomia e Documentação.

Apesar da temática da disciplina Mediação da Informação não ter ênfase exatamente na leitura, nota-se um cuidado da instituição em demonstrar 0 papel do bibliotecário enquanto mediador da informação, salientando a necessidade de capacitar o profissional para interagir com a sociedade nos mais diversos ambientes.

Afinal de contas, falar em apropriação da informação sem falar da leitura é uma tarefa incompleta, uma vez que, sem leitura não se faz mediação da informação, "[...] sem ela todas as ações realizadas nos espaços informacionais são inúteis e desprovidas de sentido, pois a informação deixa de ser apropriada" (ALMEIDA JÚNIOR, 2007, p. 35). 
Almeida Júnior (2007, p. 35) enfatiza a importância da leitura para $\mathrm{Cl}$ e Biblioteconomia:

Insistindo: a leitura é imprescindível para a Ciência da Informação e para Biblioteconomia. Sem ela, essas áreas passam a lidar com um objeto utópico. Desconsiderar a leitura ou entendê-la como de menor importância, pertencente a um campo tradicional e sem espaço nas demandas contemporâneas, é decretar a inviabilidade daquelas duas áreas.

O que Almeida Júnior quis dizer é que o objeto da $\mathrm{Cl}$ e da Biblioteconomia, só terá sentido se for consumido através da leitura. Vista para além da decodificação do significado estático de um texto, mas um processo de construção de significados em que está presente todo acúmulo social, cultural e pessoal do leitor. A esse respeito, Martín-Barbero (2009, p. 293) ratifica:

Se entendemos por leitura "a atividade por meio da qual os significados são organizados num sentido", resulta que na leitura - como no consumo - não existe apenas reprodução, mas também produção, uma produção que questiona a centralidade atribuída ao texto-rei e à mensagem entendida como lugar da verdade que circularia na comunicação. Levar a centralidade do texto à crise implica assumir como constitutiva a assimetria de demandas e competências encontradas e negociadas a partir do texto.

Na perspectiva do sujeito como produtor de sentidos, o leitor assume um papel atuante. Deixa de ser mero decodificador ou receptor passivo, passando a ser um construtor, um coautor da informação ou do texto, como destaca Almeida Júnior (2009). Abarcando essa perspectiva, a leitura é vista como imprescindível na apropriação da informação, e o leitor, ao se apropriar da informação, do texto, não o faz de forma passiva, age ativamente, construindo significados.

\section{CONSIDERAÇÕES FINAIS}

A pesquisa evidenciou que a formação do bibliotecário ainda é pouco voltada para capacitar profissionais para interagir com as ações de mediação de leitura, formação e promoção de leitura no âmbito social. A grande maioria das IES ofertam no máximo duas disciplinas obrigatórias, as quais apresentam questões voltadas para a práxis da leitura na formação do bibliotecário. 
É necessário que as instituições educacionais se sintam socialmente responsáveis por discutirem e refletirem sobre as questões sociais que cercam a sociedade no âmbito acadêmico. Ao criar condições favoráveis para que o estudante conheça os desdobramentos sociais, a universidade está promovendo a leitura da realidade do mundo e possibilitando que o senso crítico seja desenvolvido.

Para além das ações realizadas, é necessário realizar um planejamento e desenvolver estratégias que perpassam as premissas e pressupostos éticos adotados pelo projeto pedagógico das universidades. Nesse sentido, é imprescindível buscar a coerência ética que deve ser considerada entre o discurso e o que é feito na prática.

Destarte, o ensino de Biblioteconomia deve cumprir a missão de favorecer a transmissão e a comunicação de informações voltadas para o entendimento e apropriação ética da responsabilidade social do Bibliotecário, com a finalidade de produzir novos conhecimentos e apoiar as decisões na prática da mediação social da leitura.

Negligenciar os aspectos da leitura, em especial da leitura literária, pode gerar desastrosas consequências. É preciso evidenciar a responsabilidade de mediação que se confere ao bibliotecário já que ele está entre o leitor e o acesso à leitura. (ALMEIDA JUNIOR; BICHERI, 2013). Para mudar o presente cenário, é imprescindível que a formação profissional do bibliotecário the permita assumir uma postura competente e crítica da realidade na qual está inserido.

\section{REFERÊNCIAS}

AGUIAR, V. T. de. O caminho dos livros: da biblioteca à comunidade. In: AGUIAR, V. T. de; MARTHA, A. P. A. (Org.). Territórios da leitura: da literatura aos leitores. São Paulo: ANEP. 2006.

ALMEIDA JUNIOR, O. F. de. Mediação da informação e múltiplas linguagens. Pesquisa brasileira em ciência da informação, Brasília, v. 2, n. 1, p. 89-103, jan./dez. 2009. 
. Leitura, mediação e apropriação da informação. In: SANTOS, J. P.

(Org.). A leitura como prática pedagógica: na formação do profissional da informação. Rio de Janeiro: Fundação Biblioteca Nacional, 2007. p. 33-35.

Bibliotecário escolar: seu perfil, seu fazer. In: SILVA, R. J. da; BORTOLIN, S. (Org.). Fazeres cotidianos da biblioteca escolar. São Paulo: Polis, 2006.

ALMEIDA JUNIOR, O. F. de; BICHERI, A. L. A. O. Bibliotecário escolar: um mediador de leitura. Revista Ribeirão Preto, v. 2, n. 1, p. 41-54, 2013.

ASHLEY. P. A. Ética e responsabilidade social nos negócios. São Paulo: Saraiva, 2003.

BRASIL. Ministério da Educação. CNE/CES 492/2001. Diretrizes Curriculares Nacionais dos cursos de Filosofia, História, Geografia, Serviço Social, Comunicação Social, Ciências Sociais, Letras, Biblioteconomia, Arquivologia e Museologia. Diário Oficial da República Federativa do Brasil, Brasília, 9 jun. 2001, Seção 1e, p. 50.

CHARTIER, R. A aventura do livro: do leitor ao navegador. São Paulo: Fundação Editora da UNESP, 1998.

Práticas da leitura. São Paulo: Estação da liberdade, 1996. 268p.

GASQUE, K. C. G. D. Letramento Informacional: pesquisa, reflexão e aprendizagem. Brasília: Unb, 2012.

GIL, A. L. Como elaborar projetos de pesquisa. 5. ed. São Paulo: Atlas, 2010.

MADRUGA, M. L. C. B. Biblioteconomia e Inclusão Educacional: análise de propostas curriculares. Revista ACB: Biblioteconomia em Santa Catarina, v. 13, n. 1, p. 106-116, 2008. Disponível em:

<http://basessibi.c3sl.ufpr.br/brapci/index.php/article/download/11263>. Acesso em: 01 ago. 2017.

PETIT, M. Os jovens e a leitura: uma nova perspectiva. São Paulo: Editora 34, 2008.

MULLER, S. P. M. O Ensino de Biblioteconomia no Brasil. Ciência da Informação, Brasília, v. 14, n. 1, p. 3-15, jan./jun. 1985.

SOCIAL RESPONSIBILITY OF THE LIBRARIAN AS A 


\title{
LITERARY MEDIATOR: ANALYSIS IN THE CURRICULA OF UNDERGRADUATE COURSES IN LIBRARIANSHIP IN THE NORTHEAST OF BRAZIL
}

\begin{abstract}
Introduction: It discusses the importance of the formation of librarian's reading skills in the personal and professional scope, for the constitution of this professional as mediator of the reading and teacher of the subject-reader in the ambit of the libraries. Objective: To identify the subjects that approach the reading theme from the point of view of the social responsibility of the librarian as literary mediator, through the curricula of the librarianship courses of the Northeast region of Brazil. Methodology: This is a documentary research, exploratory and descriptive, and a qualitative approach. The data collection was done via the web, through the recovery of the Pedagogical Projects of Course (PPC) and the curricular matrices of the courses. Subsequently, a mapping of the curricular components that deal with the subject of reading in the subjects of the librarianship courses in the Northeast was carried out. The analysis involved the compulsory subjects offered by the universe of the nine Federal Universities of the Region that teach the Librarianship course. Results: After the mapping and identification of the compulsory subjects with reading themes within the scope of social responsibility of the mediator librarian, we had a number of six Federal Institutions, with emphasis on Librarianship courses. Conclusion: The research evidenced that the formation of the librarian is still not enough to train professionals to interact with the actions of mediation of reading, formation and promotion of reading in the social scope. The vast majority of HEls offer at most two compulsory subjects, which present questions related to the praxis of reading in the formation of the librarian.
\end{abstract}

Descriptors: Librarian. Mediation of Reading. Social responsability.

\section{RESPONSABILIDAD SOCIAL DEL BIBLIOTECARIO ENCUENTRO MEDIADOR LITERARIO: ANÁLISIS EN LOS CURRÍCULOS DE LOS CURSOS DE GRADUACIÓN EN BIBLIOTECONOMÍA EN EL NORDESTE DE BRASIL}

\begin{abstract}
RESUMEN
Introducción: Discute la importancia de la formación de competencias lectoras del bibliotecario en el ámbito personal y profesional, para la constitución de este profesional como mediador de la lectura y formador del sujeto-lector en el ámbito de las bibliotecas. Objetivo: Identificar las disciplinas que abordan la temática lectura bajo la óptica de la responsabilidad social del bibliotecario como mediador literario, a través de los currículos de los cursos de Biblioteconomía de la región Nordeste de Brasil. Metodología: Se trata de una investigación documental, de carácter exploratorio y descriptivo, y de abordaje cualiquantitativo. La recolección de los datos fue realizada vía web, a través de la recuperación de los Proyectos Pedagógicos de Curso (PPC) y de las matrices curriculares de los cursos. Posteriormente, se realizó un mapeamiento de los componentes curriculares que versan sobre la temática de la
\end{abstract}


lectura en las disciplinas de los cursos de biblioteconomía en el Nordeste. El análisis involucró las disciplinas obligatorias ofrecidas por el universo de las nueve Universidades Federales de la Región que ministra el curso de Biblioteconomía. Resultados: Después del mapeo e identificación de las disciplinas obligatorias con temáticas sobre lectura en el ámbito de la responsabilidad social del bibliotecario mediador, tuvimos un número de seis Instituciones Federales, destacándose los cursos de Biblioteconomía. Conclusión: La investigación evidenció que la formación del bibliotecario todavía está poco orientada a capacitar a profesionales para interactuar con las acciones de mediación de lectura, formación y promoción de lectura en el ámbito social. La gran mayoría de las IES ofrecen al máximo dos disciplinas obligatorias, las cuales plantean cuestiones dirigidas a la praxis de la lectura en la formación del bibliotecario.

Descriptores: Bibliotecario. Mediación de la lectura. Responsabilidad social.

Recebido: 04.03.2018

Aceitos: 31.05.2018 